\title{
THE METABOLIC SYNDROME: RELATIONSHIP BETWEEN INSULIN SENSITIVITY AND THE ROLE OF PEROXISOME PROLIFERATOR-ACTIVATED RECEPTORS (PPARs) IN SACCHARIDE AND LIPID METABOLISM
}

\author{
Rabha Ben Yahia ${ }^{a}$, Radka Lichnovskáa, Tomáš Brychta ${ }^{\mathrm{b}}$ \\ ${ }^{a}$ Institute of Physiology, Faculty of Medicine, Palacký University, 77515 Olomouc, Czech Republic \\ ${ }^{b}$ Policlinic SPEA Olomouc, Czech Republic \\ e-mail:yahiarab@yahoo.com
}

Received: June 10, 2005; Accepted: September 25, 2005

Key words: PPARs/FABP/Insulin resistance/Dyslipidemia/Atherosclerosis/Agonists

Peroxisome proliferator-activated receptors (PPARs) are subgroups of nuclear hormonal receptors of transcripting factors mostly found in adipose tissue. They are described as important regulators of lipid and saccharide metabolism including insulin sensitivity; therefore they are taken as marker of metabolic syndrome. Their synthetic ligands could be used as drugs for insulin resistance and type 2 diabetes mellitus.

\section{INTRODUCTION}

Obesity along with insulin resistance is the most frequent metabolic disease over the world. Incidence of obesity is equal to pandemy that represents a serious problem for the world health service of $21^{\text {st }}$ century. This phenomenon threatens not only the Western populations, but also the newly industrialized countries; minorities in developed countries and populations of countries that replaced their traditional life style by the Western life style. About 2.1\% of worldwide population have suffered from diabetes and an increase to $3 \%$ is expected by 2010 . This is mostly type 2 diabetes mellitus associated with insulin resistance ${ }^{33}$.

Civilization-conditioned obesity is often associated with hyperinsulinemia and insulin resistance. These factors are considered to be the main syndromes of metabolic disease comprising also dyslipidemia of certain type (hypertriglyceridemia with decreased HDL-cholesterol) and hypertension. In 1980's, Kaplan termed the complex of these diseases as "deadly quartet". Now, this complex is called metabolic syndrome X or Raven's syndrome. Progressed atherosclerosis is the main sequel of these diseases and mortality cause.

According to statistics, approximately every third adult suffers from this metabolic syndrome consisting of obesity associated with insulin resistance. Therefore efforts have been developed to find pathogenetic mechanisms of the origin of these diseases that represent predominant risk factors of cardiovascular morbidity and mortality. Individual components of metabolic syndrome are closely related and mutually conditioned, which highly increases the risk of cardiovascular diseases because the impact of these risk factors is not summed but multiplied ${ }^{9,24,25}$.

\section{MARKERS INFLUENCING INSULIN SENSITIVITY}

Up to now, numerous factors had been identified that are formed directly in adipose tissue and with increasing subcutaneous and intraabdominal fatty tissue they mostly negatively affect insulin metabolic efficiency. This is the case especially of fatty acids released in excess adipose tissue in obesity. Thus, fatty acid-binding proteins and their role in lipid metabolism seem to be crucial. Adipocytes also produce numerous polypeptides and cytokines, e.g. leptin, TNF $\alpha$, adipsin, resistin, which modulate tissue sensitivity to insulin effect and thus may be involved in etiopathogenesis of metabolic syndrome. Others factors which influence the lipid metabolism and are taken as marker of metabolic syndrome are PPARs. They represent homeostasis regulators of fatty acids and triacylglycerols in adipose tissue, which is indirectly but considerably associated with glucose metabolism homeostasis and insulin sensitivity ${ }^{15}$. In this study we will focus on PPARs.

\section{PPARS AS NUCLEAR HORMONE RECEPTORS}

The PPARs are subgroups of nuclear hormone receptors of transcription factors. Ligand-activated transcription factors are various proteins that bind the activation molecule and then conform, thus being able entering the cell nucleus and modulate DNA transcription. PPARs regulate genes controlling lipid metabolism and in return lipid metabolites regulate their activity ${ }^{19}$. They represent homeostasis regulators of fatty acids and triacylglycerols in adipose tissue, which is indirectly but considerably associated with glucose metabolism homeostasis and insulin sensitivity $^{15}$ (see Fig. 1.). 


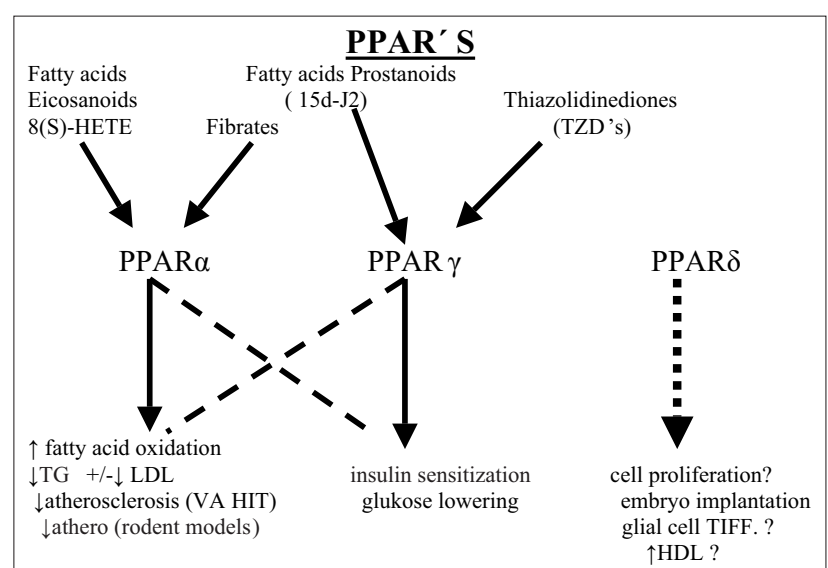

Fig. 1. Small molecule ligands can modulate one or more of each of the three PPAR isoforms.

The PPARs are considered to be lipid-activated nuclear receptors and are known to either induce transcription via PPAR response elements or inhibit transcription by inhibiting NFkb and AP-1 signalling. The binding of lipid ligands and their synthetic counterparts lead up to the recruitment of transcriptional coactivator proteins that influence the rate of RNA polymerase II transcription. The PPARs are expressed in endothelial cells which are constantly exposed to shear forces from the flow of blood along their surface. Jorge Plutzky from Harvard medical school confirmed with his recent studies the role of PPARs in vascular biology and atherosclerosis and affirmed its expression and its regulation of important target genes in relevant cell types. He provided a rationale for the large-scale cardiovascular trials with PPAR agonists now underway and their part in diabetes, inflammation and atherosclerosis ${ }^{34,20}$.

In concert, all this findings and conformations reveal previously unrecognized PPAR-sensitive pathways involved in maintenance of cholesterol homeostasis, lipid metabolism and inhibition of inflammatory responses in macrophage may be used for a development of new therapies of atherosclerosis and diabetes type II.

\section{SUBGROUPS OF PPARS}

Three types of PPAR are defined: PPAR $\alpha$, PPAR $\beta$ (also termed as beta, NUC-1 or FAAR) and PPARy. These PPARs Subgroups have different functions and diverse expression in various tissues.

PPAR $\alpha$ are in humans expressed by liver, striated muscles, kidney and cell endothelium. It participates in regulation of lipoprotein metabolism fatty acid oxidation, fatty acid uptake by cells and their alteration represents one of factors of originated disorder of lipid metabolism ${ }^{15,30}$.

PPAR $\alpha$ agonists decrease TAG plasma concentrations by decreasing apolipoprotein C-III concentrations and increasing the expression of lipoprotein lipase. It has been demonstrated that apo AV is a PPAR $\alpha$ target gene and supporting its role as a major mediator for how fibrates reduce triacylglycerols in human's and mice's plasma ${ }^{14}$. Many preclinical analyses provided that activation of PPAR $\alpha$ represents very important pathway which influences vascular function directly and indirectly by altering gene expression. PPAR $\alpha$ activation induces beneficial effects on lipid metabolism, on glucose homeostasis, on endothelial function and on vessel wall inflammation. PPAR $\alpha$ agonists can modify the process of atherosclerosis especially in patients with metabolic syndrome or type 2 diabetes ${ }^{23}$. Sweetly to all of this fact PPAR $\alpha$ agonists like the statins are beginning to have numerous additional anti-inflammatory and anti-atherosclerotic actions so they take an important place in the therapeutic arsenal for cardiovascular disease prevention ${ }^{6,27}$.

$\operatorname{PPAR} \beta / \delta$ was found in various tissues. In animals they are involved in differentiation of ologogendrocytes and spermatogenesis. PPAR $\beta$ were also found in human tissues but their distribution and function haven been studied in detail yet ${ }^{1}$.

Its role was investigated in skeletal muscle, by performing Affymetrix microarray gene expression analysis in rat treated with the PPAR $\beta / \delta$ agonist GW501516. Activation PPAR $\beta / \delta$ by this agonist evoked the clustered expression of molecules governing fatty acid oxidation and energy expenditure. Most important effect of GW501516 on tow distinct models of metabolic syndrome is embellished fatty acid oxidation in skeletal muscle, protected against dietinduced obesity and improved glucose tolerance and insulin sensitivity. So we can affirm that PPAR $\beta / \delta$ agonist could be used as ideal pharmacological target for intervention and prevention of obesity and associated metabolic diseases like type 2 diabetes mellitus. However PPAR $\beta / \delta$ as a nuclear receptor which regulates atherosclerosis- relevant genes by binding to upstream promoter elements is ubiquitously expressed and by its activation causes a decrease of plasma triacylglycerol and an elevation of HDLC. The increase of HDL production stimulates reverse cholesterol transport. Consequently, specific $\operatorname{PPAR} \beta / \delta$ agonists could be used as anti-dyslipidemic and antiatherosclerotic drugs. Moreover the PPAR $\beta / \delta$ agonists have a therapeutic effect also for obesity ${ }^{8,29,11,26}$.

PPAR $y$ are mostly expressed in adipose tissue. mRNA for PPAR $y$ and corresponding protein were found in human skeletal muscles, liver, kidney, intestine, urinary bladder and spleen. The corresponding protein for PPAR $\gamma$ was detected also in the myocardium. mRNA for PPAR $\gamma$ exist in three isoforms $\left(\gamma_{1}, \gamma_{2}, \gamma_{3}\right)$ but PPAR $\gamma$ corresponding protein only in two different isoforms $\left(\gamma_{1}, \gamma_{2}\right)$.

PPARy play a key role in adipogenesis and are major regulators of the reaction of thrifty gene responsible for effective energy storage. By influencing adipocyte regulation and stimulating neutral fat formation and storage, they represent an important factor in lipid and glucose metabolism regulation. Their synthetic ligands are efficient medicaments of insulin resistance and type 2 diabetes. Recent studies have proved that these nuclear receptors are significantly involved in transcription control and many other cell processes, e.g. control of cell cycle, carcinogenesis, inflammation, atherosclerosis and 
immunomodulation. PPAR $\gamma$ activators (e.g. thiazolidinediones) increase plasma adiponectin concentration in insulin-resistant individuals and type 2 diabetic patients via increased expression and secretion in adipocytes. PPAR $\gamma$ is expressed in two major isoforms $\gamma_{1} \gamma_{2}$. Both the structurally different isoforms are products of one gene. No functional differences were reported (see Fig. 2.). There are several factors that may affect insulin metabolism just by adiponectin secretion modulation by adipocytes. One of these factors is $\mathrm{TNF} \alpha$, which decreases adiponectin expression and secretion. PPAR $\gamma$ activation reduces nega-

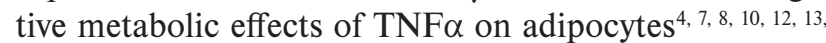
$23,22,28,31,32$

\section{THIAZOLIDINEDIONES (TZDS) AND INSULIN SENSITIVITY}

TZD represent a new category of peroral diabetics improving insulin resistance. The mechanism of their effect consists of activation of nuclear receptors PPAR $\gamma$, so that TZD influence the expression of genes coding proteins necessary for insulin effect. TZDs increase pancreas betacell activity and correct the glucose uptake in peripheral tissues. They also positively influence the blood pressure and rectify the lipid spectrum. In adipose tissue they favourably change the profile of secretion of hormones associated with insulin resistance (decrease of TNF $\alpha$, resistin, leptin and increased adiponectin level) and improve the production of free fatty acids. Through improved sensitivity to insulin, TZD affect comprehensively all components of metabolic syndrome. Clinically, TZD have been used as drugs of second choice in combination with metformin or sulphonylurea derivatives - they cannot be used in monotherapy (except e.g. USA, Finland, Switzerland, Sweden)

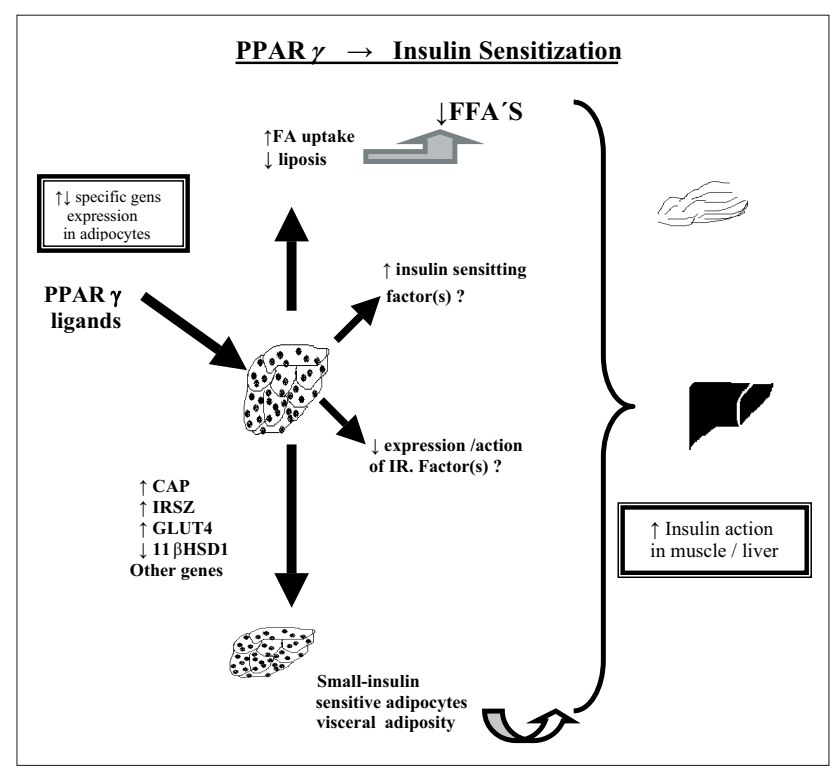

Fig. 2. Mechanisms of insulin sensitization by PPARy ligands are multifactorial and are largely mediated indirectly via PPAR $\gamma$ modulation in adipose tissue. or in combination with insulin. A standard antidiabetic therapy effects the elimination of subsequent complicates associated with type 2 DM progression, however their effects are minimally. Recent studies report that the use of TZDs either in monotherapy or in combination with used antidiabetics shows much more effect on metabolic processes that eliminate progression of type $2 \mathrm{DM}$ complications. Therefore it is recommended to apply TZD at the beginning of the therapy of type $2 \mathrm{DM}^{2,3}, 16,17,18,21$.

Synthetic PPARy agonists (e.g. TZDs) confer insulin sensitizing and anti-diabetic effects in animals and humans; they are also implicated as having anti-inflammatory and anti-atherosclerotic effects. The development of agents with dual PPAR $\gamma$ and PPAR $\gamma$ activity provides for a new approach to achieve additional efficacy with respect to controlling dyslipidemia in association with glucose lowering activity. An alternative approach is the recent discovery of synthetic PPARy ligands with partial agonist or antagonist activity (selective PPAR $\gamma$ modulators) (see Fig. 2.).

\section{THIAZOLIDINEDIONES (TZDS) AND PLASMA LIPID SPECTRUM}

People with type 2 diabetes frequently have a dyslipidemia characterized by elevated triacylglycerols, reduced high-density cholesterol and preponderance of small dense LDL particles. Importantly several studies have reported that the different components of dyslipidemia are related to insulin resistance measured either by using as a parameter either the HOMA index or insulin stimulated glucose utilization rate during insulin clamp studies. Since TZDs improve insulin sensitivity it may be expected that the effect of TZDs on lipid parameters could also be positive. Currently two agents rosiglitazone and pioglitazone are available for treatment of type 2 diabetic patients. Growing data evidence that these drugs also cause significant changes in plasma lipid concentrations. TZDs activate PPAR and modulate the expression of several genes regulating glucose and lipid metabolism. TZDs promote triacylglycerol storage in adipocyte and this is associated with reduction of FFA release into circulation. FFA flux into the liver is one major factor driving VLDL assembly and secretion from the liver. Since both pioglitazone and rosiglitazone lower plasma FFA levels to a similar magnitude one would expect a similar reduction of plasma triacylglycerol (TAG) levels. However the response of plasma TAG to TZDs has been variable in type 2 diabetic subjects. Pioglitazone seems to reduce plasma TAG level whereas rosiglitazone has minimal or no effect on plasma TAG. This difference of plasma TAG response raises the question; do TZDs have some direct effect on VLDL assembly/secretion in the liver? This option is supported by the findings that in man TZDs seems to reduce liver fat that is closely connected with the elevation of plasma TAG level. Available data evidence that TZD compounds consistently increases plasma HDL cholesterol despite the differences in plasma TAG response. 
The change of HDL cholesterol has been between ca. $5-15 \%$ in different clinical trials. The effects of TZDs on apo A-I level seem to be variable and either increase or no change has been reported. Recent findings from in vitro experiments suggest that PPAR (like PPAR activators stimulate the ABCA 1 pathway and cholesterol efflux from the cells. This mechanism provides a good explanation for the increase of HDL cholesterol without major changes of apo A-I in clinical trials. The change of LDL cholesterol has also been variable in clinical trials. The use of rosiglitazone has been associated with a small but consistent increase of LDL cholesterol whereas the response to pioglitazone seems to be neutral. Available data on the response of apo B 100 to TZDs have been inconsistent. Why TZDs exert different effects on LDL is an open issue. Preliminary data suggest that both pioglitazone and rosiglitazone may decrease the amount of small dense LDL particles but the mechanism of this action is not yet resolved. In conclusion TZDs seem to have potentially beneficial actions on lipid parameters independently on their effects on blood glucose control. However the specific sites of PPAR (activators in lipid metabolism in man are still not well understood ${ }^{23,5,28}$.

\section{CONCLUSION}

Metabolic syndrome is the most frequent disease and considered as the predominant risk factor of cardiovascular diseases. Numerous factors had been identified that are formed directly in adipose tissue and with increasing subcutaneous and intraabdominal fatty tissue they mostly negatively affect insulin metabolic efficiency. Transcription factor PPAR $\gamma$ is an important parameter regulating genes that control lipid and saccharide metabolism. The role of PPAR $y$ in regulation of saccharide and lipid homeostasis can be modulated by various factors e.g. fatty acid-binding proteins, adponectin ect. Adipocytes of obese individuals produce excessively some cytokines (including leptin and $\mathrm{TNF} \alpha$ ) that reduce sensitivity of many tissues to insulin effect. Recent papers indicate the existence of mutual relations among these cytokines, nuclear receptors PPAR $\gamma$ and adiponectin. PPAR agonists e.g. TZDs and fibrates have benefit effect in the treatment of insulin resistance associated with metabolic syndrome and in prevention of its cardiovascular complication.

\section{REFFERENCES}

1. Auboeuf D, Rieusset J, Fajas L, Vallier P, Frering V, Riou JP, Staels B, Auwerx J, Laville M, Vidal H (1997) Tissue distribution and quantification of the expression of mRNAs of peroxisome proliferator-activated receptors and liver $\mathrm{X}$ receptor-alpha in humans: no alteration in adipose tissue of obese and NIDDM patients. Diabetes 46, 1319-27.

2. Balkrishnan R, Rajagopalan R, Shenolikar RA, Camacho FT, Whitmire JT, Anderson RT (2004) Healthcare costs and prescription adherence with introduction of thiazolidinedione therapy in Medicaid type 2 diabetic patients: a retrospective data analysis. Curr Med Res Opin 20, 1633-40.
3. Bell DS, Ovalle F (2004) Outcomes of initiation of therapy with once-daily combination of a thiazolidinedione and a biguanide at an early stage of type 2 diabetes. Diabetes Obes Metab 6,363-6.

4. Boyle PJ (2004) What are the effects of peroxisome proliferatoractivated receptor agonists on adiponectin, tumor necrosis factoralpha, and other cytokines in insulin resistance? Clin Cardiol 27, 11-6.

5. Clasen R, Schupp M, Foryst-Ludwig A, Sprang C, Clemenz M, Krikov M, Thone-Reineke C, Unger T, Kintscher U (2005) PPARgamma-activating angiotensin type-1 receptor blockers induce adiponectin. Hypertension 46, 137-43.

6. Flavell DM, Ireland H, Stephens JW, Hawe E, Acharya J, Mather H, Hurel SJ, Humphries SE (2005) Peroxisome proliferator-activated receptor alpha gene variation influences age of onset and progression of type 2 diabetes. Diabetes 54, 582-6.

7. Haluzik M, Parizkova J, Haluzik MM (2004) Adiponectin and its role in the obesity-induced insulin resistance and related complications. Physiol Res 53, 123-9.

8. Hřebíček J (2004) PPAR: Úloha v homeostáze glukózy a lipidů, $\mathrm{v}$ inzulinové rezistenci a v ateroskleróze. Československá fyziologie 1, 4-16.

9. Jequir E, Tappy L (1997) Obesity. Mol Aspects Med 18, 247 305.

10. Kawaguchi K, Sugiyama T, Hibasami H, Toyoda N (2003) PPARgamma, TNF-alpha messenger RNA levels and lipase activity in the pregnant and lactating rat. Life Sci 72, 1655-63.

11. Kim DJ, Devlin MK, Bility MT, Gonzalez FJ, Billin AN, Willson TM, Peters JM (2005) PPAR $\beta(\delta)$-dependent regulation of cell proliferation, differentiation and carcinogenesis:studies from null mouse models. $3^{\text {rd }}$ International Symposium on PPARs 2005, 2.

12. Laplante M, Sell H, MacNaul KL, Richard D, Berger JP, Deshaies Y (2003) PPAR-gamma activation mediates adipose depot-specific effects on gene expression and lipoprotein lipase activity: mechanisms for modulation of postprandial lipemia and differential adipose accretion. Diabetes 52, 291-9.

13. Lazar MA (2005) PPAR gamma,10 years later. Biochimie 87, 9-13.

14. Matsuzawa Y, Funahashi T, Kihara S, Shimomura I (2004) Adiponectin and metabolic syndrome. Arterioscler Thromb Vasc Biol 24, 29-33.

15. Memon RA, Tecott LH, Nonogaki K, Beigneux A, Moser AH, Grunfeld C, Feingold KR (2000) Up-regulation of peroxisome proliferator-activated receptors (PPAR-alpha) and PPAR-gamma messenger ribonucleic acid expression in the liver in murine obesity: troglitazone induces expression of PPAR-gamma-responsive adipose tissue-specific genes in the liver of obese diabetic mice. Endocrinology 141, 4021-31.

16. Meriden T (2004) Progress with thiazolidinediones in the management of type 2 diabetes mellitus. Clin Ther 26, 177-90.

17. Miyazaki Y, Mahankali A, Wajcberg E, Bajaj M, Mandarino LJ, DeFronzo RA (2004) Effect of pioglitazone on circulating adipocytokine levels and insulin sensitivity in type 2 diabetic patients. $\mathrm{J}$ Clin Endocrinol Metab 89, 4312-9.

18. Pajvani UB, Hawkins M, Combs TP, Rajala MW, Doebber T, Berger JP, Wagner JA, Wu M, Knopps A, Xiang AH, Utzschneider KM, Kahn SE, Olefsky JM, Buchanan TA, Scherer PE (2004) Complex distribution, not absolute amount of adiponectin, correlates with thiazolidinedione-mediated improvement in insulin sensitivity. J Biol Chem 279, 12152-62.

19. Pascual G, Fong AL, Ogawa S, Gamliel A, Li AC, Perissi V, Rose DW, Willson TM, Rosenfeld MG, Glass CK (2005) A SUMOylation-dependent pathway mediates transrepression of inflammatory response genes by PPAR-gamma. Nature. 437, 759-63

20. Plutzky J (2004) PPARs: altering clinical responses in Type 2 diabetes and atherosclerosis. Introduction. Clin Cardiol 27(7 Suppl 4), IV1-2.

21. Seufert J, Lubben G, Dietrich K, Bates PC (2004) A comparison of the effects of thiazolidinediones and metformin on metabolic control in patients with type 2 diabetes mellitus. Clin Ther 26, 805-18. 
22. Shimada K, Miyazaki T, Daida H (2004) Adiponectin and atherosclerotic disease. Clin Chim Acta 344, 1-12.

23. Staels B, Fruchart JC (2005) Therapeutic roles of peroxisome proliferator-activated receptor agonists. Diabetes 54, 2460-70.

24. Svačina Š (2001) Metabolický syndrom. Triton, Praha, 179 stran.

25. Svačina Š, Owen K (2003) Syndrom inzulinové rezistence. Triton, Praha, 182 stran.

26. Tanaka T, Yamamoto J, Iwasaki S, Asaba H, Hamura H, Ikeda Y, Watanabe M, Magoori K, Ioka RX, Tachibana K, Watanabe Y, Uchiyama Y, Sumi K, Iguchi H, Ito S, Doi T, Hamakubo T, Naito M, Auwerx J, Yanagisawa M, Kodama T, Sakai J (2003) Activation of peroxisome proliferator-activated receptor delta induces fatty acid beta-oxidation in skeletal muscle and attenuates metabolic syndrome. Proc Natl Acad Sci U S A 100, 15924-9.

27. Wahli W, Tan NS, Di-Poi N, Desvergne B, Michalik L (2005) PPAR in cell survival and migration. $3^{\text {rd }}$ International Symposium on PPARs 2005.

28. Wang M, Tafuri S (2003) Modulation of PPARgamma activity with pharmaceutical agents: treatment of insulin resistance and atherosclerosis. J Cell Biochem 89, 38-47.
29. Weigand S, Bischoff H, Dittrich-Wengenroth E, Heckroth H, Lang D, Vaupel A, Woltering M (2005) Minor structural modifications convert a selective PPARalpha agonist into a potent, highly selective PPARdelta agonist. Bioorg Med Chem Lett 15, 4619-23.

30. Yajima K, Hirose H, Fujita H, Seto Y, Fujita H, Ukeda K, Miyashita K, Kawai T, Yamamoto Y, Ogawa T, Yamada T, Saruta T (2003) Combination therapy with PPARgamma and PPARalpha agonists increases glucose-stimulated insulin secretion in $\mathrm{db} / \mathrm{db}$ mice. Am J Physiol Endocrinol Metab 284, E966-71.

31. Zhang J, Fu M, Cui T, Xiong C, Xu K, Zhong W, Xiao Y, Floyd D, Liang J, Li E, Song Q, Chen YE (2004) Selective disruption of PPARgamma 2 impairs the development of adipose tissue and insulin sensitivity. Proc Natl Acad Sci U S A 101, 10703-8.

32. Zhang L, Chawla A (2004) Role of PPAR gamma in macrophage biology and atherosclerosis. Trends Endocrinol Metab 15, 500-5.

33. Zimmet P (2000) 60th Scientific Sessions of the American Diabetes Association.

34. Ziouzenkova O, Ahmed W, Orasanu G, Devchand P, Plutzky J (2005) PPARs and atherosclerosis. $3^{\text {rd }}$ International Symposium on PPARs 2005, 1. 